\title{
One-step green synthesis and characterization of leaf extract-mediated biocompatible silver and gold nanoparticles from Memecylon umbellatum
}

This article was published in the following Dove Press journal:

International Journal of Nanomedicine

25 March 2013

Number of times this article has been viewed

\author{
Kantha D Arunachalam \\ Sathesh Kumar Annamalai \\ Shanmugasundaram Hari \\ Center for Environmental Nuclear \\ Research, Directorate of Research, \\ SRM University, Chennai, Tamil Nadu, \\ India
}

\begin{abstract}
In this experiment, green-synthesized silver and gold nanoparticles were produced rapidly by treating silver and gold ions with an extract of Memecylon umbellatum leaf. The reaction process was simple and easy to handle, and was monitored using ultraviolet-visible spectroscopy. The effect of the phytochemicals present in M. umbellatum, including saponins, phenolic compounds, phytosterols, and quinones, on formation of stable silver and gold nanoparticles was investigated by Fourier-transform infrared spectroscopy. The morphology and crystalline phase of the nanoparticles were determined by transmission electron microscopy and energy-dispersive x-ray spectroscopy. The results indicate that the saponins, phytosterols, and phenolic compounds present in the plant extract play a major role in formation of silver and gold nanoparticles in their respective ions in solution. The characteristics of the nanoparticles formed suggest application of silver and gold nanoparticles as chemical sensors in the future. Given the simple and eco-friendly approach for synthesis, these nanoparticles could easily be commercialized for large-scale production.
\end{abstract}

Keywords: green synthesis, phytochemicals, saponins, nanoparticles, transmission electron microscopy

\section{Introduction}

Silver nanoparticles are widely used in industry and have an inhibitory effect on a number of microorganisms. They have also been used in the manufacture of ointments and creams to prevent infection of burns and wounds. ${ }^{1}$ Organic solvents have been used for green synthesis of nanoparticles, with water in particular being an important solvent for bioreduction. ${ }^{2}$ Green synthesis is an alternative harmless and environment-friendly method for producing nanoparticles. ${ }^{3}$ Triangular-shaped and spherical-shaped gold nanoparticles have been used for detection of DNA and as an immunoassay system for antibodies. ${ }^{4}$ The use of nanoparticles as potential drug carriers in the treatment of cancer has also been reported.

Nanoparticles can be prepared using a variety of chemicals and physical methods, including chemical reduction, ${ }^{5-7}$ photochemical reduction, ${ }^{8-11}$ electrochemical reduction, ${ }^{12,13}$ and heat vaporization. ${ }^{14,15}$ The reagents can be inorganic compounds, such as sodium/potassium borohydrate, hydrazine, and salts of tartrate, or organic compounds, like sodium citrate, ascorbic acid, and amino acids, which are capable of being oxidized. Because noble metal nanoparticles are now widely used in areas of human contact, ${ }^{16}$ there is a growing need to develop environmentally friendly processes that do not use toxic chemicals in their synthesis. A quest for an environmentally
Correspondence: Kantha D Arunachalam Center for Environmental Nuclear Research, Directorate of Research, SRM University, Chennai, Tamil Nadu 603203, India

Tel +9| $44274|7| 44$

Fax $+9|44274| 7 \mid 46$

Email kanthad.arunachalam@gmail.com 
sustainable synthetic process has led to several biomimetic approaches, one of the fundamental processes of which involves bioreduction.

To overcome the problem of toxicity in synthesis, plants have come to have a major role in the synthesis of nanoparticles. The different-shaped polyol and water-soluble heterocyclic components of plant biomolecules have both protective and reductive activity, and are mainly responsible for the reduction of silver and gold ions using chemical and radiation methods. In recent years, extracellular silver and gold nanoparticles were synthesized using various plantmediated extracts as a reducing agent.

Memecylon umbellatum is a well known herbal drug in India. Its leaves are used for their astringent, antispasmodic, antitumor, and neuroleptic activities, as well as to treat leucorrhoea and gonorrhea. A lotion prepared from its leaves is used to treat eye troubles, ${ }^{17}$ and the leaves and bark can be applied to bruises. ${ }^{18} \mathrm{M}$. umbellatum belongs to the Melastomataceae family, which is the seventh largest family of flowering plants and originates from India.

To date, there is no report of synthesis of silver and gold nanoparticles utilizing an aqueous leaf extract of M. umbellatum. In this experiment, M. umbellatum extract in a concentrated aqueous solution of silver nitrate and chloroauric acid resulted in reduction of silver and gold ions and formation of silver and gold nanoparticles. These greensynthesized nanoparticles were examined by ultravioletvisible spectroscopy, transmission electron microscopy (TEM), energy dispersive X-ray analysis (EDAX), and Fourier transform infrared (FTIR) spectroscopy to determine their size and shape.

\section{Materials and methods Collection of plants}

The M. umbellatum plant material was collected from the Potheri forest in Tamil Nadu, India The herbarium was prepared, submitted, and authenticated by Dr Jayaraman, Madras Christian College, Tambaram, Chennai, Tamil Nadu.

\section{Preparation of aqueous extract}

The leaves of the plants collected were washed and air-dried in the shade at room temperature for at least two weeks, cut into small pieces, powdered in a mixer, and sieved using a $20 \mu \mathrm{m}$ mesh sieve to obtain a uniform size range for further study. Next, $20.0 \mathrm{~g}$ of the sieved leaf powder was added to $100 \mathrm{~mL}$ of sterile distilled water in a $500 \mathrm{~mL}$ Erlenmeyer flask and boiled for 5 minutes. The flasks were kept under continuous dark conditions at $30^{\circ} \mathrm{C}$. The extract was filtered and stored at $4^{\circ} \mathrm{C}$ for further experiments.

\section{Phytochemical activity}

Qualitative phytochemical analysis of the M. umbellatum extract was performed using the methodology described by Parekh and Chanda ${ }^{19}$ for determining the presence of alkaloids (Mayer's, Wagner's, Dragendorff's reagents), flavonoids (Shinoda alkaline reagent), phenolic compounds (lead acetate, alkaline reagent test), triterpenes (LibermanBurchard test), saponins (foam test), and tannins (gelatin). ${ }^{20-23}$ The results of these tests were expressed qualitatively as positive $(+)$ or negative $(-)$.

\section{Antimicrobial activity}

Antimicrobial tests were done by the disc-diffusion method (Murray et al, 1995) using $100 \mu \mathrm{L}$ of suspension containing $10^{8}$ colony-forming units per $\mathrm{mL}$ of bacteria on Mueller Hinton agar. Six-millimeter diameter discs were impregnated with $10 \mu \mathrm{L}$ of the extract ( $300 \mu \mathrm{g}$ per disc) at a concentration of $30 \mathrm{mg} / \mathrm{mL}$ and placed on agar plates inoculated with common clinically encountered pathogens. Negative controls were prepared using the same solvents as those used to dissolve the plant extracts. Ofloxacin (10 $\mu \mathrm{g}$ per disc), ciprofloxacin (10 $\mu \mathrm{g}$ per disc), and netilmicin (30 $\mu \mathrm{g}$ per disc) were used as positive reference standards to determine the sensitivity of one strain per isolate for each microbial species tested. The inoculated plates were incubated at $37^{\circ} \mathrm{C}$ for 24 hours to obtain the bacterial strains. Antimicrobial activity was evaluated in duplicate by measuring the zone of inhibition for the test organisms. ${ }^{22}$ The antimicrobial activity of M. umbellatum extract was evaluated for Bacillus subtilis, Streptococcus pneumoniae, Staphylococcus aureus, Salmonella typhimurium, Klebsiella aerogenes, and Escherichia coli.

\section{One-step green synthesis of silver and gold nanoparticles using leaf extract}

Silver nitrate and chloroauric acid were purchased from Sigma-Aldrich (St Louis, MO), and the aqueous leaf extract of $M$. umbellatum was used for the bioreduction process. To synthesize nanoparticles from M. umbellatum, 5, 10, and $15 \mathrm{~mL}$ of the aqueous leaf extract were carefully added to $10 \mathrm{~mL}$ of $1 \mathrm{mM}$ aqueous silver nitrate and chloroauric acid solution in $250 \mathrm{~mL}$ Erlenmeyer flasks. The flasks containing the extract were incubated on a rotary shaker at $150 \mathrm{rpm}$ in dark conditions. A change in color of the colloidal 
solutions occurred, confirming green synthesis of silver and gold nanoparticles. ${ }^{24}$

\section{Ultraviolet-visible absorbance spectroscopy}

Bioreduction of the nanoparticles by silver nitrate and chloroauric acid was monitored using a Series 3000 double beam ultraviolet-visible spectrophotometer (Thermo Fisher Scientific, Waltham, MA, USA) with slit widths of $0.5,1.0$, 2.0 , and $5.0 \mathrm{~nm}$. The samples used for analysis were diluted with $2 \mathrm{~mL}$ of deionized water and subsequently measured in the ultraviolet-visible spectrum at regular time intervals. ${ }^{25}$ Deionized water was used for background correction of all ultraviolet-visible spectra. Samples were loaded into a $1 \mathrm{~cm}$ path length quartz cuvette for investigation. The ultravioletvisible spectra were fitted to Gaussian curves correcting for a cubic background for full-width at half maximum and wavelength of maximum absorbance measurements. All Gaussian fits to the ultraviolet-visible spectra had goodness of fit values ( $\chi^{2}$ approximately 1$)$ indicating accurate curve analysis. ${ }^{26}$ The ultraviolet-visible spectrophotometric readings were recorded at a scanning speed of $0.5 \mathrm{~nm}$ intervals. The spectrum was scanned from $200 \mathrm{~nm}$ to $800 \mathrm{~nm}$.

\section{Transmission electron microscopy}

Thirty minutes after reaction, the biomass had settled at the bottom of the conical flasks, and samples of the suspended precipitate were taken for observation by TEM. Samples of the green-synthesized silver and gold nanoparticles were prepared by placing a drop of the suspension on carbon-coated copper grids, allowing the films on the TEM grids to stand for two minutes, removing the excess solution with blotting paper, and letting the grid dry prior to measurement. TEM observations were performed using an H7600 instrument (Hitachi, Tokyo, Japan) operated at an accelerating voltage of $100 \mathrm{kV}$. The size distribution of the nanoparticles was estimated based on TEM images using Sigma Scan Pro software version 4.01.003 (SPSS Inc, Chicago, IL). ${ }^{27}$

\section{FTIR spectroscopy}

A carefully weighed quantity of green-synthesized silver and gold nanoparticle powder was subjected to FTIR analysis. The bioreduced chloroauric acid and silver nitrate solutions were centrifuged at $10,000 \mathrm{rpm}$ for 15 minutes, and the pellet was washed three times with $20 \mathrm{~mL}$ of deionized water. The resulting purified suspension was completely dried, ground with $\mathrm{KBr}$ pellets, and analyzed by FTIR. A total of
512 scans were recorded in order to obtain a good signal to noise ratio. ${ }^{28}$

\section{EDAX spectroscopy}

Energy-dispersive X-ray spectroscopes exploit the photon nature of light. In the X-ray range, the energy of a single photon is just sufficient to produce a measurable X-ray voltage pulse, and the output of an ultralow noise preamplifier connected to the low noise constitutes a statistical measure of the corresponding quantum energy. By digitally recording and counting a large number of such pulses within a so-called multichannel analyzer, a complete image of the X-ray spectrum is built up almost simultaneously. This digital quantum counting technique makes energy-dispersive X-ray spectroscopy very reliable. A semiconductor material is used to detect the X-rays together with processing electronics to analyze the spectrum. The gold and silver solutions reduced by $M$. umbellatum extract were dried, drop-coated onto carbon film, and tested using an EDAX spectrometer (S-3400N, Hitachi).

\section{Results and discussion Phytochemical screening}

The aqueous extract of $M$. umbellatum was evaluated for the presence of various phytoconstituents by performing a series of qualitative chemical tests. Phytochemicals in the aqueous extract of $M$. umbellatum are shown in Table 1, and include primarily saponins, phytosterols, phenolic compounds, quinones, carbohydrates, and protein. The aqueous M. umbellatum leaf extract was found to have a high saponin content, suggesting that saponins are the most favorable starting material for preparation of these nanoparticles. The pharmacological activity of saponin and its multiple medicinal properties have also been reported for other plant species. Early studies by Raut et $\mathrm{al}^{25}$ demonstrated that

Table I Preliminary phytochemical investigation of aqueous extract of Memecylon umbellatum

\begin{tabular}{ll}
\hline Phytochemicals & Aqueous extract \\
\hline Alkaloids & - \\
Phytosterol & + \\
Saponin & + \\
Phenolic compounds & + \\
Catechins & - \\
Flavonol glycosides & - \\
Quinones & + \\
Phlobatannins & - \\
Steroids & - \\
\hline
\end{tabular}

Notes: +, presence; -, absence. 
nanoparticles formed using saponin from an aqueous extract of Panax ginseng have strong activity in upregulation of the immune response in mice. Phytosterol-based nanoparticles form stable suspensions of submicron particles, which are not soluble in water. ${ }^{29}$ Production of nanoparticles at room temperature aided by tautomerization of membrane-bound quinones has also been reported..$^{30}$

\section{Antimicrobial activity}

The antimicrobial activity of the aqueous $M$. umbellatum extracts was investigated, with their potency assessed quantitatively by the zone of inhibition and zone diameter using Pseudomonas aeruginosa, Streptococcus pyogenes, Enterococcus faecalis, Proteus vulgaris, Proteus mirabilis, Citrobacter freundii, and E. coli. The calculated zones of inhibition are shown in Table 2.

\section{Ultraviolet-visible spectrometry}

Ultraviolet-visible spectrometry was used to examine the size and shape of the nanoparticles in aqueous suspension. The aqueous plant extracts acted as reducing and capping agents for the nanoparticles. Reduction of silver ions by combinations of biomolecules found in these extracts, including enzymes/proteins, amino acids, polysaccharides, and vitamins, is environmentally benign but chemically complex. However, the mechanism is widely accepted for green synthesis of silver and gold nanoparticles in the presence of the nitrate reductase enzyme. Aqueous silver nitrate $(10 \mathrm{~mL}, 1 \mathrm{mM})$ was used to investigate the effect of including different amounts of the dried biomass on the extent of bioreduction and uniformity of the target products. The amount of dried biomass was found to play a critical role in the size distribution of silver nanoparticles. Figure 1 shows the absorption spectra for silver nanoparticles produced at different time intervals, revealing that these nanoparticles were produced within one hour of the silver ions coming in contact with the biomass. After addition of the biomass to the solution of silver nitrate, the solution

Table 2 Antimicrobial activity of Memecylon umbellatum extracts (300 $\mu \mathrm{g}$ per disc)

\begin{tabular}{ll}
\hline Organism & Zone of inhibition $\mathbf{( m m})$ \\
\hline Pseudomonas aeruginosa & 10.0 \\
Streptococcus pyogenes & 14.5 \\
Enterococcus faecalis & 6.9 \\
Proteus vulgaris & 9.7 \\
Proteus mirabilis & 10.3 \\
Citrobacter freundii & 9.4 \\
Escherichia coli & 7.4 \\
\hline
\end{tabular}

changed from colorless to brown color in about one hour, with the final color deepening on increasing the amount of dried biomass. Evolution of the absorbance spectra emanating from the silver nanoparticles over time showed increasingly sharp absorbance at around $440 \mathrm{~nm}$ with increasing reaction time.

Saponins and phenolic compounds present in plant extracts bind to nanoparticles via either free amine groups or cysteine residues in proteins. ${ }^{31}$ Saponins, phenolic compounds, and quinones from $M$. umbellatum capped the silver nanoparticles, thereby stabilizing them. To conclude, water-soluble fractions comprised of saponins, phenolic compounds, and quinones in the aqueous plant extract helped in the bioreduction of silver ions.

Reduction of gold ions to gold nanoparticles on exposure to the plant leaf extract was detected by a change in color. Ultraviolet-visible spectra recorded at different time intervals for the reaction with aqueous chloroauric acid solution showed appearance of a surface plasmon resonance band at about $540 \mathrm{~nm}$ after two minutes of reaction. From Figure 2, it is evident that the peak wavelength did not shift during the reaction. Thus, we could monitor the concentrations of gold nanoparticles quantitatively by measuring absorbance at $540 \mathrm{~nm}$.

\section{Transmission electron microscopy}

\section{Silver nanoparticles}

Analysis of the bioreduced green-synthesized silver nanoparticles by TEM confirmed that they were in the nanorange, approximately spherical in shape, and had a mean diameter of 15-20 nm after 24 hours. A representative TEM image is shown in Figure 3. Most of the nanoparticles were roughly circular in shape with smooth edges. Some nanoparticles had anisotropic structures with irregular contours, as shown in Figure 4. It can be seen that most of the silver nanoparticles in the TEM images are in close physical contact but separated by a fairly uniform interparticle distance.

\section{Gold nanoparticles}

The morphology and size of the green-synthesized gold nanoparticles determined by TEM are shown in Figure 5. The particles formed were spherical, hexagonal, and triangular in shape as shown in Figure 6. The nanotriangles formed were monodispersed and had a large surface area of 15-25 (mean 17) nm, with only a few particles being outside this size range.

The biomolecules acted as capping agents, supporting the formation of spherical-shaped nanoparticles rather than 


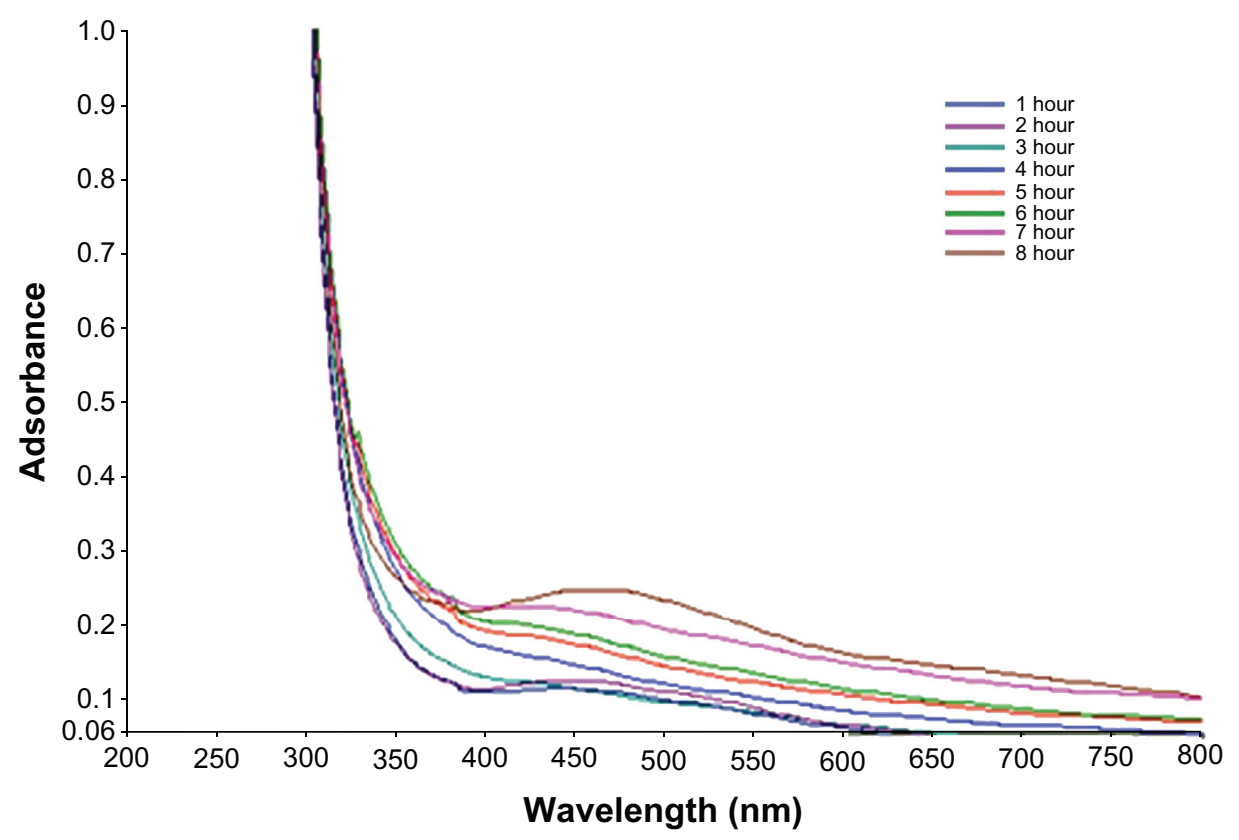

Figure I Absorption spectra of silver nanoparticles after bioreduction of Memecylon umbellatum aqueous.

the formation of triangular or hexagonal nanostructures. High magnification of TEM images recorded during our earlier research showed that biologically synthesized gold nanoparticles at the end of reaction with Memecylon edule leaf extract were also predominantly triangular, circular, and hexagonal in morphology. A large quantity of circular gold nanoparticles with thin smooth ends on the exterior of the nanoparticles was seen in the TEM images (Figure 6). Small amounts of the extract could reduce the chloroaurate ions, but did not protect most of the semispherical nanoparticles from aggregating because of the inability of biomolecules to act as protecting agents, and this was clearly observed in the TEM images.

\section{Energy-dispersive X-ray spectroscopy Silver nanoparticles}

EDAX spectroscopy confirmed the presence of an elemental silver signal from the silver nanoparticles, as

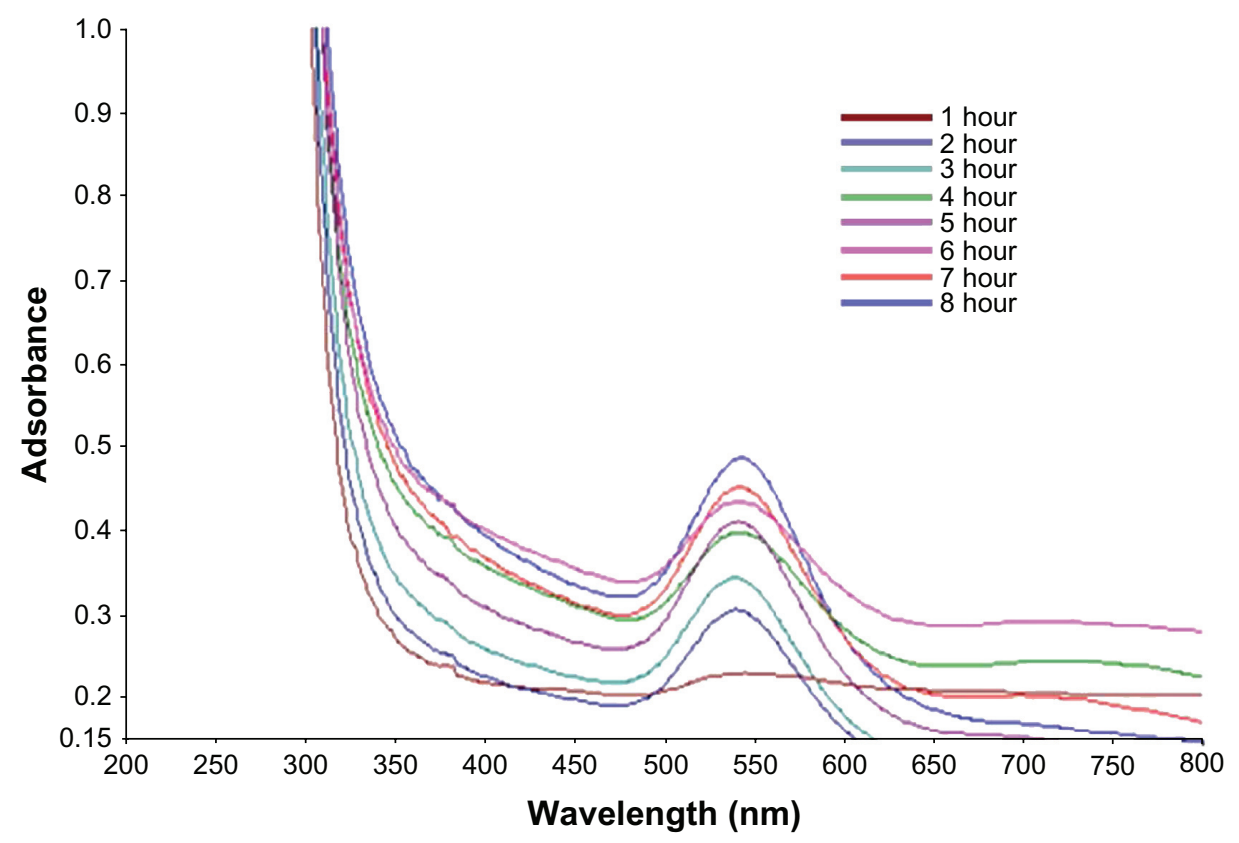

Figure 2 Absorption spectra of gold nanoparticles after bio reduction with $0.5 \mathrm{~mL}$ of Memecylon umbellatum aqueous extract. 


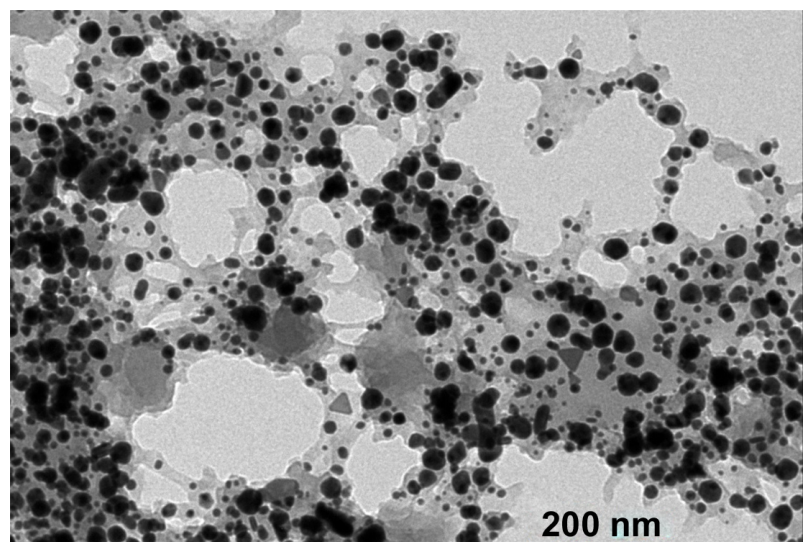

Figure 3 Transmission electron microscopy images of silver nanoparticles after bioreduction with Memecylon umbellatum.

shown in Figure 7. The vertical axis shows the number of $\mathrm{X}$-ray counts and the horizontal axis shows energy in keV. Identification lines for the major emission energies for silver are shown and these correspond with peaks in the spectrum, indicating that silver was correctly identified.

The EDAX profile for the silver nanoparticles showed strong silver signals from silver atoms (Figure 7). The EDAX pattern shows clearly that the silver nanoparticles were crystalline in nature due to the reduction of silver ions using the M. umbellatum leaf extract. The present study confirmed the presence of silver nanoparticles formed using M. umbellatum and showed strong signal energy peaks for silver atoms in the range $2-4 \mathrm{keV}$ and weaker signals for carbon, oxygen and chloride, which were provenients from biomolecules of M. umbellatum. In an earlier study, ${ }^{24}$ we identified signal energy peaks in the range of $2-4 \mathrm{keV}$ for spherical-shaped silver nanoparticles produced using M. edule. Our findings

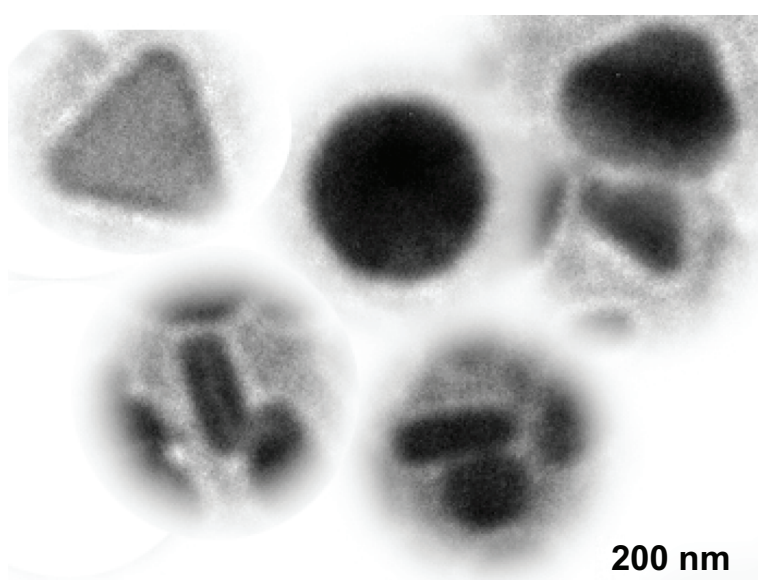

Figure 4 Representative high magnification transmission electron microscopy micrograph of a single silver nano triangle, circular, spindle, hexagonshaped nanoparticles.

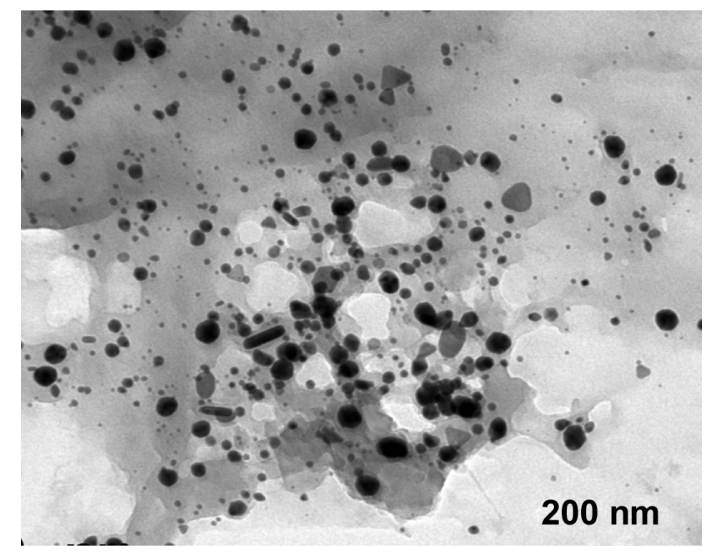

Figure 5 Transmission electron microscopy images of gold nanoparticles after bioreduction with Memecylon umbellatum.

are similar to those for the Chenopodium album leaf extract reported by Dwivedi et $\mathrm{al}^{32}$ and for Cassia auriculata reported by Kumar et al. ${ }^{33}$

\section{Gold nanoparticles}

The green-synthesized gold nanoparticles were investigated further using EDAX spectrometry, which confirmed the presence of gold with no contaminants. The optical adsorption peak was observed at approximately $2.30 \mathrm{keV}$ (Figure 8), which is typical of adsorption of gold nanocrystallites due to surface plasmon resonance. The EDAX profile for gold nanoparticles synthesized using $M$. umbellatum showed strong gold atom signals at around 2.30, 8.10, 9.40, and $11.30 \mathrm{keV}$. EDAX for the gold nanoparticles showed strong signals for gold atoms and weaker signals for carbon, oxygen, and chloride, which were provenients from biomolecules of M. umbellatum, and the strong signals obtained at around

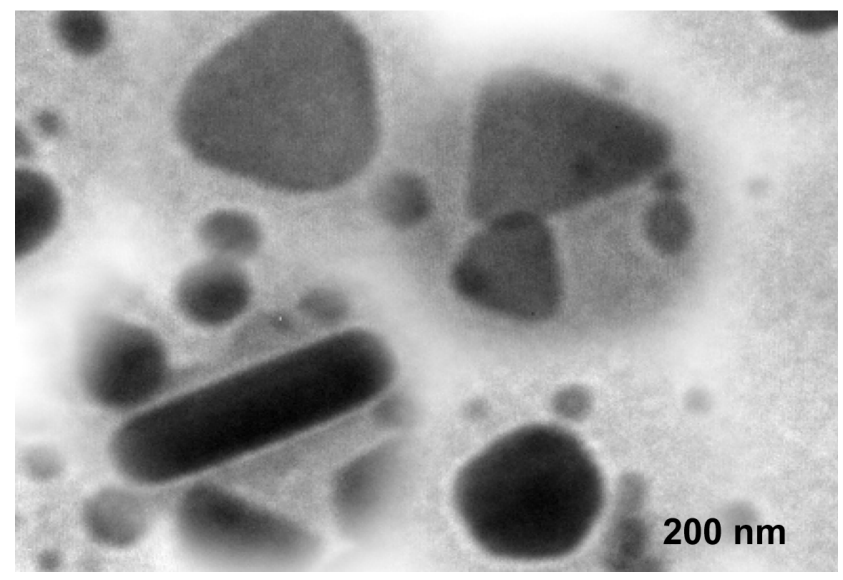

Figure 6 Representative high magnification transmission electron microscopy micrograph of a single gold nano triangle, circular, spindle, hexagon shaped nanoparticles. 


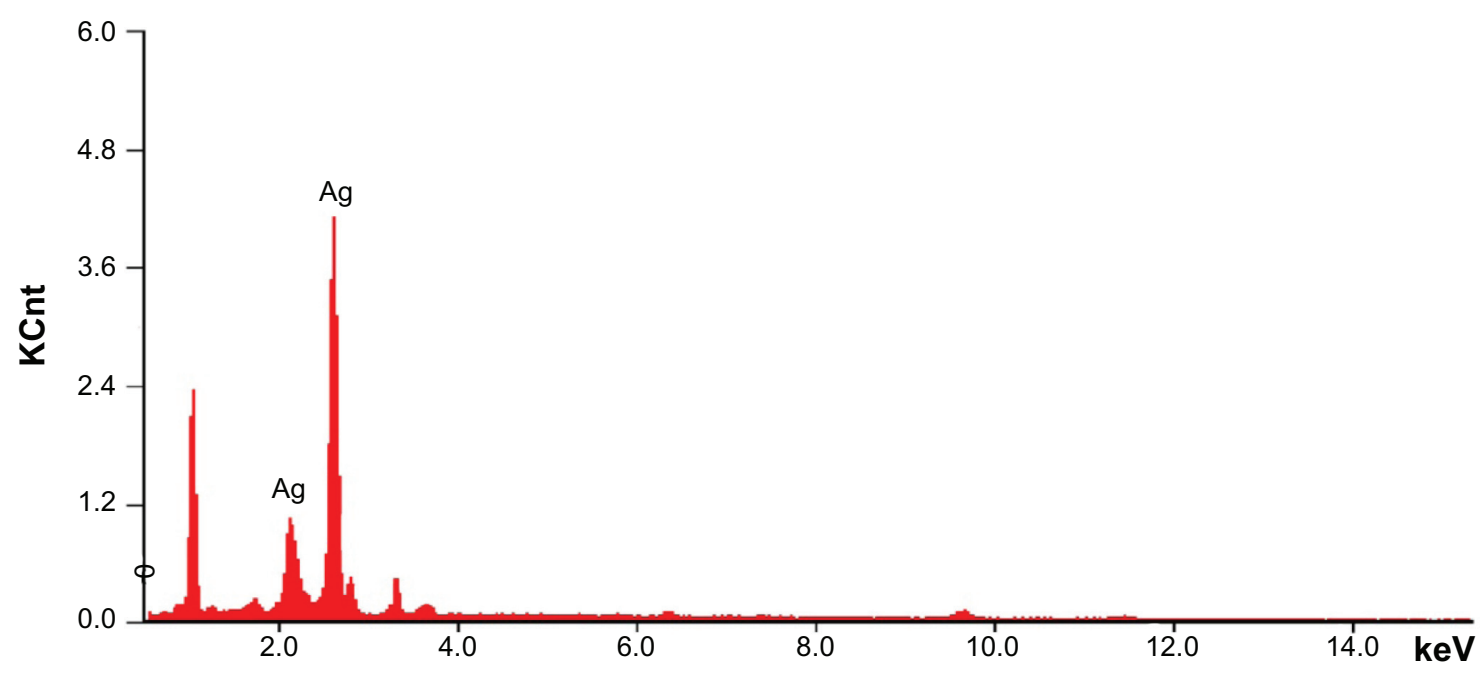

Figure 7 EDAX profile of synthesized silver nanoparticles.

Abbreviation: EDAX, energy dispersive $\mathrm{X}$-ray spectroscopy.

$2.30 \mathrm{keV}$ and $9 \mathrm{keV}$ were similar to those in our earlier studies. $^{24}$

\section{Fourier transform infrared spectroscopy}

Size distribution and characterization of the green-synthesized silver nanoparticles were explored further using FTIR. The interaction of nanoparticles with phytochemicals of M. umbellatum showed intense peaks at 2884, 1600, 1507, 1387,1074 , and $1335 \mathrm{~cm}^{-1}$ relative shift in position and intensity distribution were confirmed with FTIR (Figure 9). The FTIR recorded for the dry $M$. umbellatum powder showed strong bands at 2832, 1731, 1612, and $1403 \mathrm{~cm}^{-1}$. Comparing the FTIR spectra, it can be seen that for changes in the $-\mathrm{COOH}$ group for $-\mathrm{OH}$, ie, the hydroxyl group, the peak appeared at $3316 \mathrm{~cm}^{-1}$ in the raw material, but after encapsulation of nanoparticles, the peak was narrower and shifted to $3635 \mathrm{~cm}^{-1}$, and the peak intensity reduced also for the $-\mathrm{C}$ - of the carboxylic group after encapsulation of nanoparticles. $\mathrm{H}$ bonds can be formed between the amide groups. As the plant molecules became adsorbed onto the surface of the green-synthesized silver nanoparticles, the amide groups tended to form stronger bonds with the silver atoms, breaking most of the $\mathrm{H}$ bonds between the $\mathrm{N}-\mathrm{H}$ groups and leading to narrowing and blue shifts in the amide bond. The band appearing at $1387 \mathrm{~cm}^{-1}$ corresponds to $\mathrm{C}-\mathrm{N}$ stretching of the amine group, and in the raw extract, the peak was broad and blends, but after encapsulation of nanoparticles, this peak was narrow and sharper. This implies that the $-\mathrm{COOH}$ group in the compound was attached to the gold nanoparticles and there is a clear change in the spectra. After encapsulation, the $1731 \mathrm{~cm}^{-1}$ in $-\mathrm{C}-$ bond stretching becomes masked or disappears.

Overall, it can be concluded that the $M$. umbellatum proteins adsorb as a layer over the green-synthesized silver nanoparticles, which stabilizes them. It is well known that proteins can bind to silver and gold nanoparticles via either free amine groups or cysteine residues in the saponins,

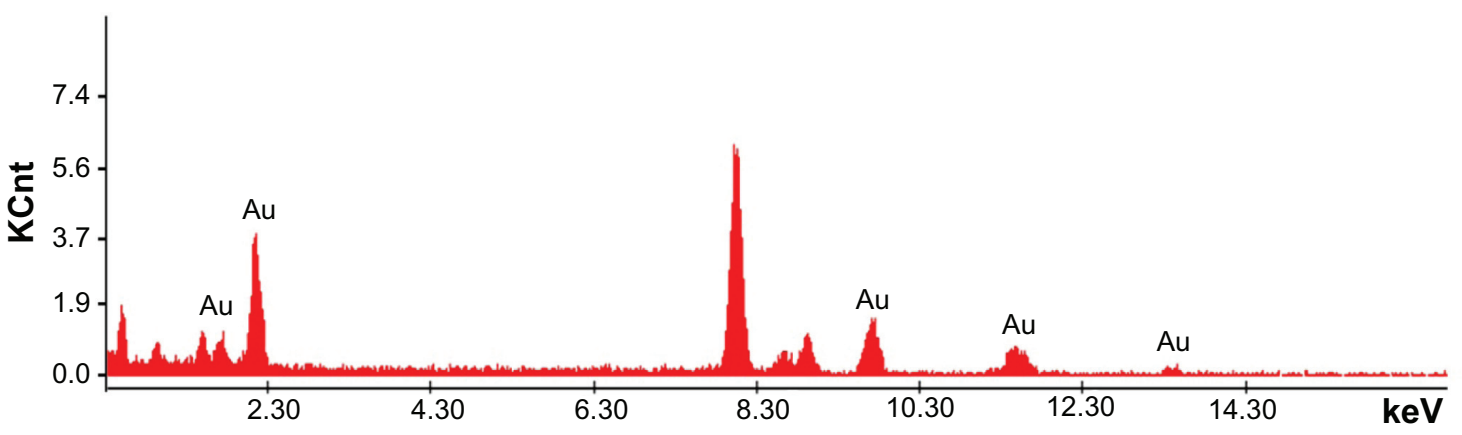

Figure 8 EDAX spectrum of gold nanoparticles.

Abbreviation: EDAX, energy dispersive $\mathrm{X}$-ray spectroscopy. 


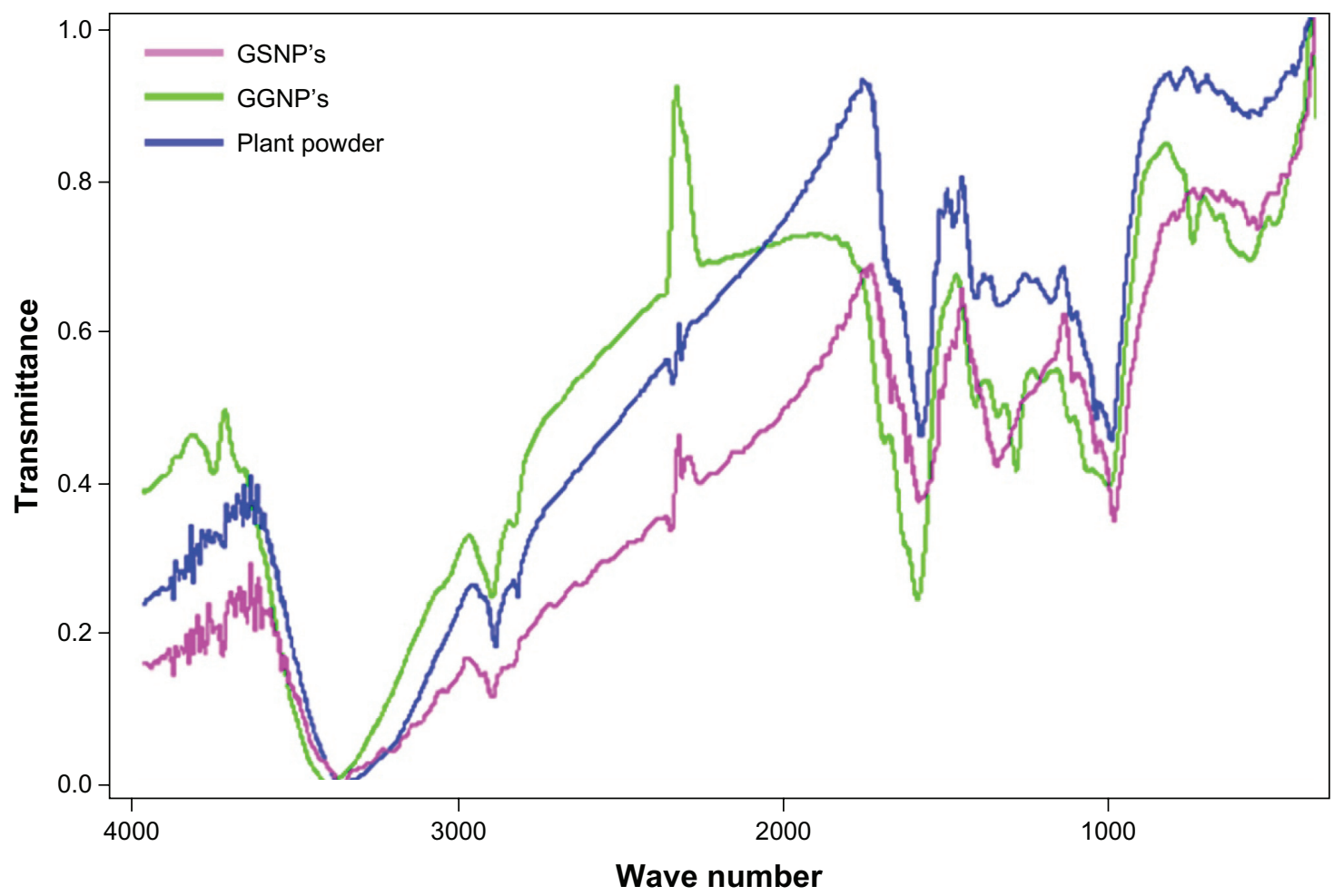

Figure 9 Typical FTIR spectrum of GSNP's and GGNP's from M. umbellatum aqueous leaf extracts.

Abbreviations: FTIR, Fourier transform infrared spectroscopy; GSNP, green synthesized silver nanoparticle; GGNP, green synthesized gold nanoparticle.

phenolic compounds, and quinones from M. umbellatum, thereby stabilizing the nanoparticles formed through the surface-bound proteins.

\section{Conclusion}

The present study demonstrates bioreductive synthesis of nanosized silver and gold particles using M. umbellatum. The M. umbellatum aqueous leaf extract appears to be environmentally friendly, so that this protocol could be used for rapid production of silver and gold nanoparticles. The size of the nanoparticles can be easily adjusted by using different amounts of leaf extract. In the future, selection of such plants may create a new platform for realizing the potential of herbal medicines in nanoscience for drug delivery and biomedical application. This is a preliminary study of the biological mechanism for biosynthesis of nanoparticles and a first step in controlling their size. In addition, this report provides a theoretical and experimental foundation for investigations of the biosynthesis of other metal nanoparticles.

\section{Acknowledgments}

The authors acknowledge the support of the Directorate of Research, SRM University, Kattankulathur. We thank the School of Pharmacy, SRM University, for the FTIR analysis in this research. The authors also thank Dr Narasiman,
Centre for Floristic Research, Department of Botany, Madras Christian College, Chennai, Tamil Nadu, India, for identification of the plant sample.

\section{Disclosure}

The authors report no conflicts of interest in this work.

\section{References}

1. Satyavani K, Ramanathan T, Gurudeeban S. Plant-mediated synthesis of biomedical silver nanoparticles by using leaf extract of Citrullus colocynthis. Research Journal of Nanoscience and Nanotechnology. 2011;1:95-101.

2. Wu W, He Q, Jiang C. Magnetic iron oxide nanoparticles: synthesis and surface functionalization strategies. Nanoscale Res Lett. 200;3: 397-415.

3. Wang Z, Hu J, Jin Y, Yao X, Lia J. In situ amplified chemiluminescent detection of DNA and immunoassay of IgG using special-shaped gold nanoparticles as label. Clin Chem. 2006;52:1958-1961.

4. Hojo K, Hara A, Kitai H, et al. Development of a method for environmentally friendly chemical peptide synthesis in water using water-dispersible amino acid nanoparticles. Chemistry Central Journal. 2011;5:49.

5. Yu DG. Formation of colloidal silver nanoparticles stabilized by $\mathrm{Na}$-poly(gamma-glutamic acid)-silver nitrate complex via chemical reduction process. Colloids Surf B Biointerfaces. 2007;59:171-178.

6. Tan Y, Wang Y, Jiang L, Zhu D. Thiosalicylic acid-functionalized silver nanoparticles synthesized in one-phase system. J Colloid Interface Sci. 2002;249:336-345.

7. Vorobyova SA, Lesnikovich AI, Sobal NS. Preparation of silver nanoparticles by interphase reduction. Colloids Surf A Physicochem Eng Asp. 1999;152:375-379.

8. Mallick K, Witcombb MJ, Scurrella MS. Self-assembly of silver nanoparticles in a polymer solvent: formation of a nanochain through nanoscale soldering. Mater Chem Phys. 2005;90:221-224. 
9. Keki A, Torok J, Deak G, et al. Silver nanoparticles by PAMAM-assisted photochemical reduction of Ag+. J Colloid Interface Sci. 2000;229: 550-553.

10. Pileni MP. Fabrication and physical properties of self-organized silver nanocrystals. Pure Appl Chem. 2000;72:53-65.

11. Sun Y-P, Atorngitjawat P, Meziani MJ. Preparation of silver nanoparticles via rapid expansion of water in carbon dioxide microemulsion into reductant solution. Langmuir. 2001;17:5707-5710.

12. Liu YC, Lin LH. New pathway for the synthesis of ultrafine silver nanoparticles from bulk silver substrates in aqueous solutions by sono electrochemical methods. Electrochem Commun. 2004;6:1163-1168.

13. Sandmann G, Dietz H, Plieth W. Preparation of silver nanoparticles on ITO surfaces by a double-pulse method. JElectroanal Chem. 2000;491: 78-86.

14. Bae CH, Nam SH, Park SM. Formation of silver nanoparticles by laser ablation of a silver target in $\mathrm{NaCl}$ solution. Appl Surf Sci. 2002;197-198: 628-634.

15. Smetanaa AB, Klabunde KJ, Sorensen CM. Synthesis of spherical silver nanoparticles by digestive ripening, stabilization with various agents, and their 3-D and 2-D super-lattice formation. J Colloid Interface Sci. 2005;284:521-526.

16. Song JY, Kim BS. Biological synthesis of bimetallic Au/Ag nanoparticles using Persimmon (Diopyros kaki) leaf extract. Korean J Chem Eng. 2008;25:808-811.

17. The Wealth of India. A Dictionary of Indian Raw Materials and Industrial Products. New Delhi, India: National Institute of Science Communication and Information Resources; 1998.

18. Dhar ML, Dhar MM, Dhawan BN, Mehrotra BN, Ray C. Screening of Indian plants for biological activity: Part 1. Indian J Exp Biol. 1968;6: 232-247.

19. Parekh J, Chanda SV. In vitro antimicrobial activity and phytochemical analysis of some Indian medicinal plants. Turk J Biol. 2008;31: 53-58.

20. Harborne JB. Phytochemical Methods, 2nd ed. London, UK: Chapman and Hall Ltd; 1976.
21. Dey PM, Harborne JB. Methods in Plant Biochemistry. London, UK Academic Press; 1987.

22. Subhashini S, Arunachalam KA, Kumar A. Preclinical studies on the phytochemical, antimicrobial, and wound healing properties of Indigofera aspalathoides leaves. J Pharm Res. 2011;4:3206-3211.

23. Arunachalam KA, Subhashini S, Annamalai SK. Wound healing and antigenotoxic activities of Aegle marmelos with relation to its antioxidant properties. J Pharm Res. 2012;5:1492-1502.

24. Elavazhagan T, Arunachalam KA. Memecylon edule leaf extract mediated green synthesis of silver and gold nanoparticles. Int $J$ Nanomedicine. 2011;6:1265-1278.

25. Raut RW, Lakkakula JR, Kolekar NS, Mendhulkar VD, Kashid SB. Photosynthesis of silver nanoparticles using Gliricidia sepium (Jacq). Curr Nanosci. 2009;5:117-122.

26. Von White G II, Kerscher K, Brown RM, et al. Green synthesis of robust, biocompatible silver nanoparticles using garlic extract. Journal of Nanomaterials. 2012;2012:730-746.

27. Li C-M, Robertson IM, Jenkins ML, Hutchison JL, Doole RC. In situ TEM observation of the nucleation and growth of silver oxide nanoparticles. Micron. 2005;36:9-15.

28. Narayanan B, Sakthivel N. Coriander leaf mediated biosynthesis of gold nanoparticles. Mater Lett. 2008;62:4588-4590.

29. Türk M, Lietzow R. Stabilized nanoparticles of phytosterol by rapid expansion from supercritical solution into aqueous solution. AAPS Pharm Sci Tech. 2004;5:36-45.

30. Jha AK, Prasadb K, Prasad K. A green low-cost biosynthesis of $\mathrm{Sb}_{2} \mathrm{O}_{3}$ nanoparticles. Biochem Eng J. 2009;43:303-306.

31. Shankar SS, Ahmad A, Sastry M. Geranium leaf assisted biosynthesis of silver nanoparticles. Biotechnol Prog. 2003;19:1627-1631.

32. Dwivedi AD, Gopal K. Biosynthesis of silver and gold nanoparticles using Chenopodium album leaf extract. Colloids Surf A Physicochem Eng Asp. 2010;369:27-33.

33. Kumar VG, et al. Facile green synthesis of gold nanoparticles using leaf extract of antidiabetic potent Cassia auriculata. Colloids Surf B Biointerfaces. 2011;87:159-163.
International Journal of Nanomedicine

\section{Publish your work in this journal}

The International Journal of Nanomedicine is an international, peerreviewed journal focusing on the application of nanotechnology in diagnostics, therapeutics, and drug delivery systems throughout the biomedical field. This journal is indexed on PubMed Central, MedLine, CAS, SciSearch $\AA$, Current Contents ${ }^{\circledR} /$ Clinical Medicine,

\section{Dovepress}

Journal Citation Reports/Science Edition, EMBase, Scopus and the Elsevier Bibliographic databases. The manuscript management system is completely online and includes a very quick and fair peer-review system, which is all easy to use. Visit http://www.dovepress.com/ testimonials.php to read real quotes from published authors. 